\title{
Identidade e constituição do sujeito "mulher idosa" em webtirinhas da Dona Anésia
}

Identity and constitution of the subject "elderly woman" in webtirinhas of Dona Anésia

\author{
Loraine Vidigal Lisboa ${ }^{1}$ \\ Instituto Federal do Triângulo Mineiro - campus Uberaba \\ loraine_vidigal@yahoo.com.br \\ Grenissa Bonvino Stafuzza ${ }^{2}$ \\ Universidade Federal de Catalão - UFCAT \\ grenissa@gmail.com
}

\begin{abstract}
RESUMO: Temos como objetivo analisar a identidade e a constituição do sujeito "mulher idosa" a partir do gênero discursivo webtirinha. Para o trabalho, elegemos três webtirinhas da Dona Anésia, de autoria do cartunista Will Leite, publicadas em seu site WillTirando, com a proposta de mostrar como as identidades são construídas em um processo dialógico entre sujeitos a partir de enunciados verbovisuais. Assim, os sentidos que emergem das webtiras configuram como o sujeito idoso é visto socialmente e de que modo a personagem Dona Anésia promove uma ruptura, deslocando os sentidos do que se espera socialmente de uma mulher idosa. Para isso, nos pautamos na concepção dialógica da linguagem desenvolvida pelo Círculo de Bakhtin, na produção da identidade pela diferença em Silva (2000) e pela cultura da convergência midiática em Jenkins (2008).
\end{abstract}

Palavras-chave: Sujeito; Identidade; Gênero discursivo; Mulher idosa; Dona Anésia.

\begin{abstract}
We aim to analyze the identity and the constitution of the subject "elderly woman" from the discursive gender webtirinha. For the discussion, we elected three webtirinhas of Dona Anésia, authored by cartoonist Will Leite, published on his website WillTirando, in order to demonstrate how identities are constructed in a dialogical process among subjects present on verb-visual utterances. Thus, the meanings that emerge from the webtirinhas outline how the elderly subject is socially seen and, in what way, the character Dona Anésia promotes a rupture, displacing the senses of what is socially expected of an elderly woman. For this, we are oriented by the dialogical conception of language developed by the Bakhtin Circle, in the production of identity and by difference in Silva (2000) and by culture of media convergence in Jenkins (2008).
\end{abstract}

Keywords: Subject; Identity; Discursive gender; Elderly woman; Dona Anésia.

\footnotetext{
${ }^{1}$ Professora de Língua Portuguesa, Literatura e Inglês com atuação no ensino médio, técnico e superior do Instituto Federal do Triangulo Mineiro, campus Uberaba. Doutoranda no Programa de Pós-graduação em Estudos da Linguagem da Universidade Federal de Catalão (PPGEL/UFCAT).

${ }^{2}$ Professora da Unidade Acadêmica de Letras e Linguística da Universidade Federal de Catalão, onde atua na graduação e na pós-graduação, no Programa em Estudos da Linguagem (PPGEL/UFCAT). É líder do GEDIS Grupo de Estudos Discursivos (GEDIS/CNPq).
} 
Loraine Vidigal Lisboa; Grenissa Bonvino Stafuzza. Identidade e constituição do sujeito "mulher idosa" em webtirinhas da Dona Anésia.

Nada deveria ser mais esperado e, no entanto, nada é mais imprevisto que a velhice (BEAUVOIR, 1970, p. 11).

\section{Introdução}

A internet e as mídias digitais, em geral, têm se constituído em espaços de enfrentamento de discursos, assim como possibilitadoras da manifestação de diversos gêneros discursivos verbovisuais. Ao considerarmos que o sujeito se constitui a partir das relações com o outro, compreendemos que essas relações só são possivelmente materializadas por gêneros discursivos oriundos de esferas de atividades humanas diversas (BAKHTIN, 2019). Assim, temos o intuito de discutir, neste trabalho, a identidade e a constituição do sujeito "mulher idosa" a partir da análise de enunciados verbovisuais de webtirinhas da Dona Anésia, uma personagem que não se enquadra em estereótipos preestabelecidos.

Para o trabalho proposto, elegemos três webtirinhas da Dona Anésia, selecionadas no site WillTirando, criadas pelo cartunista Will Leite, que trazem em sua constituição enunciados verbovisuais característicos da arquitetônica deste gênero discursivo, sobre o qual discorremos brevemente. A escolha das tiras da Dona Anésia, além da especificidade de sua constituição verbovisual, nos interpela por tratar-se de discursos a respeito de sujeitos idosos, especialmente no que se refere ao comportamento e às identidades que são/devem ser determinados a eles culturalmente.

As webtirinhas da Dona Anésia promovem discussões, via discurso, sobre paradigmas e estereótipos a respeito do sujeito velho/idoso arraigados em nossa sociedade. Buscamos entender, se a quebra desses padrões possibilita a constituição desses sujeitos, sobretudo, no que diz respeito à "mulher idosa", e se possibilita, também, múltiplas identidades que emergem a partir de tais enunciados de materialidade verbovisual.

Para a realização do estudo, pautamo-nos na concepção dialógica da linguagem oriunda dos postulados desenvolvidos pelo Círculo de Bakhtin sobre os conceitos de discurso, esferas de atividade, gênero discursivo, sujeito e alteridade; no conceito de cultura da convergência midiática debatida por Jenkins (2008), na produção da identidade pela diferença discutida por Silva (2000) e no percurso histórico das identidades atreladas ao processo de envelhecimento em Silva (2008). 


\section{Webtirinhas: do papel para a internet e da internet para o papel}

As tirinhas são um gênero discursivo verbovisual produzidas na esfera jornalística há mais de cem anos, sendo publicadas em jornais e revistas impressas, geralmente nas páginas de entretenimento. Por serem pequenas, rápidas e de fácil leitura, caíram no gosto popular no Brasil, a partir da década de 1970. À medida que foram ganhando espaço, consolidaram-se como um gênero que traz críticas em seus temas, de maneira irônica e satírica. Segundo Nicolau (2007), as tiras são:

uma piada curta de um, dois, três ou até quatro quadrinhos, e geralmente envolve personagens fixos: um personagem principal em torno do qual gravitam outros. Mesmo que se trate de personagens de épocas remotas, países diferentes ou ainda animais, representam o que há de universal na condição humana (NICOLAU, 2007, p. 25).

Como vários outros gêneros, as tirinhas têm migrado para a esfera virtual, mantendo algumas características, recebendo outras, transformando-se continuamente. No livro Cultura da Convergência, Jenkins (2008) estabelece o conceito homônimo ao título do livro e explicita sobre a convergência dos meios de comunicação, em que as mídias tradicionais e as mídias alternativas se convergem (e seus diversos suportes - tais como impressos, digitais e audiovisuais) com o intuito de abranger a transmissão de conteúdo, além de favorecer a interação entre seu conteúdo e o público.

Dessa forma, o ambiente virtual torna-se campo profícuo para a emergência de novos gêneros discursivos e enunciados de inúmeras materialidades. Velhas e novas mídias se colidem e interagem entre si, transformando conteúdos, atualizando suportes, mudando a língua e a linguagem, emergindo novos gêneros, ressignificando a maneira como os sujeitos discursivos comunicam e, consequentemente, se constituem.

Mesmo tendo seu surgimento no jornal impresso, a convergência entre as mídias possibilita outras maneiras de elaborar as tirinhas (assim como os quadrinhos, os cartuns, as charges, entre outros) e, até mesmo, o surgimento de novos gêneros discursivos, como os memes, por exemplo (LISBOA, 2015). As tirinhas, antes produzidas no papel, com lápis, pincéis e tintas, passam a ser elaboradas, também, em mesas digitalizadoras, com a ajuda de programas de computador e acessórios diversos. 
Este é o caso das tirinhas produzidas e veiculadas no site WillTirando, canal oficial de divulgação da Dona Anésia ${ }^{3}$. A personagem criada pelo cartunista paranaense Will Leite foi publicada, pela primeira vez, em 2011 e já conta com mais de um milhão de seguidores em sua página no Facebook ${ }^{4}$. Sua criação ocorre diretamente em uma mesa digitalizadora e os traços feitos pelo cartunista espelham-se no computador a ela ligado. Nesse processo, os desenhos não são feitos à mão no papel e, em seguida, digitalizados, como normalmente acontece com as tirinhas tradicionais que migram para o ambiente online. Ao contrário, a trajetória de criação e finalização das tiras é integralmente virtual, por isso, ela é denominada webtirinha ou tira online ${ }^{5}$.

Em contexto de convergência cultural, Jenkins (2008) discorre, também, sobre cultura participativa, ou seja, a possibilidade de o público participar da elaboração de determinado produto ou serviço e de influenciar/decidir resultados de programas de TV, tais como realities shows, por exemplo. Nesse conceito, a participação da audiência (ou pelo menos parte dela) integra a divulgação da marca, do programa ou do artista. Esta maneira de conceber a produção está presente, em partes, na criação das tiras online do site WillTirando. As tiras feitas inicialmente para amigos e família passam a ser incorporadas, assimiladas e divulgadas nos espaços virtuais, e ganham corpo e visibilidade decorrente da convergência midiática e da participação do público na elaboração deste entretenimento que ele mesmo consome.

O sucesso das webtirinhas da Dona Anésia abre campo para a divulgação de outras elaborações do site WillTirando. O nicho se expande tanto em quantidade de novas tiras e personagens quanto em abrangência de veículos que as divulgam. Vale destacar que a página da Dona Anésia na rede social ${ }^{6}$ Facebook tem mais de 1,3 milhões de seguidores. Tanta visibilidade exige que tais tirinhas sejam veiculadas em outras mídias e não somente nas digitais, ocorrendo, então, o caminho inverso: as tirinhas da Dona Anésia viraram livro.

A esse fenômeno atrelamos outro conceito trabalhado por Jenkins (2008), a economia afetiva, ou seja, criar outros produtos que se vinculam de maneira afetiva ao original, propiciando fidelidade à marca e tornando o consumidor promotor desta marca. No caso da Dona Anésia, a publicação do livro impresso só foi possível devido à participação de seus leitores que, por meio de uma campanha de arrecadação de fundos, puderam vir a ter o exemplar em casa.

\footnotetext{
${ }^{3}$ Link para acesso: <http://www.willtirando.com.br/>. Acesso em: 15 jun. 2020.

${ }^{4}$ Link para acesso: <https://www.facebook.com/tirinhasanesia/>. Acesso em: 15 jun. 2020.

${ }^{5}$ Por se tratar de um gênero discursivo recente, é possível encontrar outras formas de nomear as webtirinhas nas diversas esferas de atividade nas quais ela surge.

${ }^{6}$ Ver a discussão a respeito das redes sociais como lugares de emersão de novos gêneros discursivos verbovisuais em Lisboa (2015).
} 
A obra é um compilado das melhores webtirinhas da Dona Anésia, publicadas entre 2011 e 2016, e dispõe, também, de uma história original com 60 páginas, possibilitando o consumo de um produto inédito, mas ligado ao original. Além da campanha de arrecadação para a publicação do livro, outros itens são comercializados no site, tais como canecas, botons, imãs de geladeira, cadernos, calendários, chaveiros e, até mesmo, bonecos da protagonista. Dessa maneira, a Dona Anésia, personagem de tirinhas, passa a ser, também, uma marca. A partir do exemplo acima, conseguimos visualizar a integração entre as mídias e não o apagamento de algumas em detrimento da ascensão de outras, sendo essa uma das consequências da convergência cultural debatida por Jenkins (2008).

\section{Gênero do discurso webtirinha: um enunciado verbovisual digital}

Bakhtin (2017) observa que a "arquitetônica" diz respeito à organização do espaçotempo-sentido, sendo o todo arquitetônico a interação entre material, forma e conteúdo, tanto para a atividade autoral quanto para a construção do gênero do discurso, aqui o gênero do discurso webtirinha. Nesse sentido, o enunciado verbovisual digital pode ser caracterizado "como uma unidade semioticamente complexa 'para a' e 'na' produção de sentidos" (STAFUZZA, 2018, p. 139), que circula nas diversas esferas de comunicação tecnológica e digital como, por exemplo, plataformas, redes sociais, sites, blogs etc. Assim, os sentidos que emergem do enunciado verbovisual digital só são possíveis porque suas partes imagética e verbal em tela digital não se separam no todo arquitetônico.

Ao falar de convergência cultural, especialmente a que se dá entre mídias, é imprescindível lembrar que, segundo a concepção dialógica da linguagem preconizada pelo Círculo de Bakhtin, o surgimento dos gêneros discursivos (sejam eles primários ou secundários), assim como a transformação de gêneros existentes em novos gêneros, são determinados a partir das esferas de atividade humana pelas quais os sujeitos discursivos comunicam, pois:

A riqueza e a diversidade dos gêneros do discurso são infinitas porque são inesgotáveis as possibilidades da multifacetada atividade humana e porque cada campo dessa atividade vem sendo elaborado todo um repertório de gêneros do discurso, que cresce e se diferencia à medida que tal campo se desenvolve e ganha complexidade (BAKHTIN, 2019, p. 12, grifo nosso). 
Nesse sentido, a cultura da convergência debate sobre a interação/coalisão entre as mídias, que são espaços de emergência, transformação e adaptação de gêneros discursivos. Esses ambientes, enquanto esferas de atividade humana, proporcionam a comunicação discursiva entre sujeitos situados em determinados lugares sócio-histórico-ideológicos. O resultado deste fenômeno é uma ampla diversidade de gêneros discursivos no que se refere à materialidade, e impossíveis de serem contabilizados.

Ao nascer, um novo gênero nunca suprime nem substitui quaisquer gêneros já existentes. Qualquer gênero novo nada mais faz que completar os velhos, apenas amplia o círculo de gêneros já existentes. Ora, cada gênero tem seu campo predominante de existência em relação ao qual é insubstituível [...] Ao mesmo tempo, porém, cada novo gênero essencial e importante, uma vez surgido, influencia todo dizer, mais conscientes, fá-los melhor conscientizar os seus recursos e limitações, ou seja, superar a sua ingenuidade (BAKHTIN, 2010, p. $340)$.

Sob essa perspectiva, entendemos que os gêneros do discurso são compostos por enunciados relativamente estáveis, únicos e irrepetíveis, como desenvolvido por Bakhtin (constituídos por construção composicional, conteúdo temático e estilo), sendo o enunciado a unidade mínima da comunicação discursiva, pelo qual o discurso emerge e a ele temos acesso. Estando indissociáveis em uma cadeia constante - discurso e enunciado - eles se constituem e se completam na alternância entre os sujeitos do discurso, ou seja, nas relações dialógicas. Assim, a comunicação discursiva para o Círculo está:

\begin{abstract}
Distante da perspectiva positivista de várias correntes da linguística dos séculos XIX e XX, que compreendem a comunicação como um processo linear e passivo entre as funções de "locutor" e "ouvinte" (ou "receptor"), a comunicação pensada pelo Círculo russo mostra-se um processo bastante complexo entre falantes, situado em um dado tempo e espaço, marcadamente social. Em relação à materialidade, especialmente os escritos de Bakhtin, Medviédev e Volóchinov apontam que a comunicação - realizada por meio da fala e da escrita - apresenta-se constituída pelas instâncias verbal, visual e vocal, sendo possível o estudo da voz, da entonação, da gestualidade, da imagem etc. (STAFUZZA, 2019, p. 74).
\end{abstract}

Vale ressaltar que é por meio dos enunciados que os sujeitos interagem e, nesse processo de interação discursiva, se constituem. Os enunciados são materializados em semioses diversas (verbais, visuais, vocais etc.), por isso nos valemos das webtirinhas da Dona Anésia (oriundas da convergência entre mídias e da ascensão tecnológica dos computadores e seus programas, adereços e aplicativos, promovendo novas esferas de atividade humana) para buscar entender como esses enunciados possibilitam a(s) 
identidade(s) do idoso e sua constituição como sujeito discursivo e dialógico. Partimos do pressuposto de que "o discurso humano é um fenômeno biface: todo enunciado exige, para que se realize, a presença simultânea de um locutor e de um ouvinte”, sendo, então, toda expressão linguística "orientada em direção ao outro, em direção ao ouvinte, mesmo quando este outro se encontra fisicamente ausente" (VOLOSHINOV, 1930, p. 1).

Desta feita, a presente discussão se baseia na prerrogativa da concepção dialógica da linguagem preconizada pelo Círculo de Bakhtin de que o sujeito se constitui em movimento de interação discursiva com outros sujeitos por meio do discurso, que só pode ser acessado via enunciados, materializados em diversas semioses. Sendo assim, "somente na comunicação, na interação do homem com o homem revela-se o 'homem no homem' para outros ou para si mesmo" (BAKHTIN, 2010, p. 292), ou seja, o sujeito é constituído via alteridade pela alternância dialógica de si com o outro, em momento de comunicação discursiva, de interação, de troca (mesmo que não presencial), sempre por meio do discurso.

\section{Identidade e constituição do sujeito "mulher idosa" nas webtirinhas da Dona Anésia - Falo mesmo!}

Entendemos que o sujeito se constitui a partir das relações dialógicas que estabelece consigo mesmo e com o outro, por meio dos discursos que emergem via infinitos gêneros discursivos e enunciados relativamente estáveis de materialidades diversas. Nesse sentido, é possível reconhecer a produção da identidade do sujeito "mulher idosa" a partir das webtirinhas da Dona Anésia? Como uma webtirinha, veiculada em um blog (também visto como um site comercial $)^{7}$, pode promover a constituição do(s) sujeito(s) e qual/quais identidade(s) pode $(\mathrm{m})$ ser produzidas a partir destes enunciados?

Conforme dissemos, as webtirinhas da Dona Anésia são feitas uma a uma, em uma mesa digitalizadora e sua finalização ocorre por meio de programas e aplicativos de computador. Tais enunciados verbovisuais têm como personagem principal a Dona Anésia, uma senhora idosa viúva que vive sozinha, mas está sempre em companhia da melhor amiga Dolores, de suas duas filhas, alguns netos, netas e amigas (e, eventualmente, um admirador aparece nas cenas). A característica marcante desta personagem é a sinceridade, vista pelas

\footnotetext{
${ }^{7}$ Além da veiculação das webtirinhas, o site comercializa produtos diversos, inclusive há a possiblidade de se cadastrar como membro para contribuir com doações e pagamentos, receber webtirinhas exclusivas e pontos que podem ser trocados por produtos.
} 
pessoas que convivem com ela como rispidez, ironia e sarcasmo. É aí que ocorre grande parte do humor nas tiras da Dona Anésia, pois a idade avançada nos remete, culturalmente, a pessoas dóceis, tenras, pacíficas e passivas. A quebra de expectativa, peculiar de gêneros discursivos pautados no humor, se dá no comportamento da Dona Anésia em questões corriqueiras do dia a dia.

A melhor amiga da Dona Anésia, Dolores, age completamente diferente da amiga e se enquadra na perspectiva de senhora idosa da qual estamos acostumados, é sempre amável com todos e não aparenta, nunca, ter algum tipo de rancor pela forma como é tratada pela Anésia, pelo contrário. Sendo a conduta e a personalidade das duas antagônicas, fica clara a dicotomia entre o que se espera de uma mulher idosa (ternura-Dolores) e o oposto disso (rispidez-Anésia).

Nesse sentido, entendemos que "a identidade e a diferença estão em uma relação de estreita dependência" (SILVA, 2000, p. 74), ou seja, para que a identidade possa existir é preciso haver todo o espectro que dela se difere. Anésia e Dolores, portanto, distinguem-se entre si e, dessa forma, "identificam-se". Nesse sentido, "assim como a identidade depende da diferença, a diferença depende da identidade. Identidade e diferença são, pois, inseparáveis" e “vistas como mutuamente determinadas" (SILVA, 2000, p. 75-76), reconhecidas como processo e não produto. Em consonância a isso:

\begin{abstract}
Além de serem interdependentes, identidade e diferença partilham uma importante característica: elas são o resultado de atos de criação linguística. Dizer que são o resultado de atos de criação significa dizer que não são "elementos" da natureza, que não são essências, que não são coisas que estejam simplesmente aí, à espera de serem reveladas ou descobertas, respeitadas ou toleradas. A identidade e a diferença têm que ser ativamente produzidas. Elas não são criaturas do mundo natural ou de um mundo transcendental, mas do mundo cultural e social. Somos nós que as fabricamos, no contexto de relações culturais e sociais. A identidade e a diferença são criações sociais e culturais (SILVA, 2000, p. 76, grifo nosso).
\end{abstract}

Isso significa dizer que as identidades não são estanques, ao contrário, é por meio dos embates ideológicos possibilitados pelo discurso, em acontecimentos linguageiros diários, que as identidades acontecem, sempre em movimento dialético com as diferenças.

Sobre o tema idosos, é importante contextualizar que a categorização da sociedade em faixas etárias é algo relativamente recente, que se inicia no século XIX. Dentre essas categorias está a "velhice" reconhecida (assim como outras fases, tais como a infância e a adolescência) "como uma etapa única tanto de um processo histórico amplo [...] quanto de uma tendência contínua em direção à segregação das idades na família e no espaço social" 
(SILVA, 2008, p. 157). Tal segregação faz com que a "velhice" seja colocada de lado, pois há uma prevalência pelas fases anteriores a ela, consideradas mais saudáveis e produtivas.

Segundo Beauvoir (1970), em sua obra $A$ velhice, neste período da vida há um processo denominado "conspiração do silêncio", ou seja, o apagamento do sujeito que tem mais idade, sendo o silêncio uma resposta dada à velhice pelas sociedades modernas. Seu intuito, nesta obra, é mobilizar a situação de abandono e estimular o cuidado à velhice. Indo ao encontro da denúncia a respeito do abandono para com as pessoas idosas debatida por Beauvoir, a formação de novos saberes médicos e sociais investidos a respeito do corpo envelhecido, a institucionalização das aposentadorias e o aumento na expectativa de vida dos mais velhos, dentre outros fatores, proporcionaram novas vistas para a velhice e, nesse sentido:

O surgimento da categoria 'terceira idade' é considerado, pela literatura especializada, uma das maiores transformações por que passou a história da velhice. De fato, a modificação da sensibilidade investida sobre a velhice acabou gerando uma profunda inversão dos valores a ela atribuídos: antes entendida como decadência física e invalidez, momento de descanso e quietude no qual imperavam a solidão e o isolamento afetivo, passa a significar o momento do lazer, propício à realização pessoal que ficou incompleta na juventude, à criação de novos hábitos, hobbies e habilidades e ao cultivo de laços afetivos e amorosos alternativos à família (SILVA, 2008, p. 161).

O aumento da expectativa de vida e o reconhecimento dos diversos saberes a respeito dos idosos - em contexto de emergente sociedade industrial e, logo mais tarde, em sociedade de consumo - fazem com que a mídia e o mercado percebam a oportunidade de os alocarem em novos nichos mercadológicos, possibilitando sua inserção em mercados desenvolvidos e direcionados especialmente para esse grupo, instaurando outras maneiras de reconhecimento deles pelo mercado, por si mesmos e pela sociedade em geral $^{8}$.

Tais mudanças de paradigmas e de categorização de "velhos" para "idosos" e de "velhice" para "terceira idade" abrem espaço para a emergência de novos termos, tais como "melhor idade", por exemplo. Algumas atitudes estão vinculadas a essa nomenclatura (que não é oficial), no entanto, tal expressão "parece sinalizar uma forma estereotipada de falar

\footnotetext{
${ }^{8}$ Nessa nova concepção sobre a velhice e o sujeito idoso, várias empresas ampliaram seus mercados para atenderem à nova clientela. $\mathrm{O}$ turismo, por exemplo, investiu muito em publicidade para idosos, com a ideia de que após a aposentadoria esse grupo tem tempo para viajar. Algumas agências são, inclusive, popularmente conhecidas e estereotipadas como "agências da terceira idade". Nessa abertura, é possível perceber que o elemento que marca o idoso enquanto idoso persiste até mesmo quando a publicidade tenta alcançá-lo: o idoso permanece considerado como "improdutivo", por isso, pode viajar a qualquer momento. Além disso, os produtos que são ofertados para os idosos nas publicidades são sempre aqueles que o marcam enquanto idoso.
} 
sobre o idoso, a qual vem sendo constantemente retomada, reatualizada, mas também deslocada e/ou negada nos espaços em que ela circula” (NAVARRO, 2011, p. 1552).

A veiculação de novos termos para se referir a esta etapa da vida faculta a concreta 'invenção' de uma nova identidade a partir da simples adesão ao novo estilo de vida que está atrelado à alimentação saudável, prática de exercícios físicos e, especialmente, socialização, tratando-se, supostamente, da "melhor fase da vida". Dessa forma, o nicho de pessoas acima de 60, 65 anos passa a ser o de um grupo ativo, produtivo e consumidor e, para que tal ideia ganhe força, é preciso incuti-la na sociedade em geral, especialmente, entre os próprios sujeitos idosos. Convencê-los, portanto, de que a fase em que estão é para aproveitarem a vida, retomarem projetos adiados, terem lazer e se socializarem, sendo tudo isso possível como consequência da mudança de hábitos e atitudes que darão a eles uma vivência feliz e saudável. Essa mudança de pensamento e postura irá refletir diretamente no retorno aos mercados destinados a esse grupo.

Instaura-se como uma categoria de sujeitos autônomos e protagonistas, com vivências, experiências, comportamentos e saberes específicos, as identidades dos idosos se constituem a partir das diferenças com outros sujeitos, inseridos em outras categorias e suas peculiaridades, já que a "idade passou a ser um fator fundamental para a distinção social, destacando-se como categoria e como modelo de identidade para os sujeitos" (SILVA, 2008, p. 157). Mas, mesmo com as mudanças gradativas e importantes nos paradigmas sobre o sujeito que deixa de ser "velho" e passa a ser "idoso", ainda estão arraigados na memória da sociedade comportamentos, atitudes, corpos e espaços específicos para eles e, por isso, flutuar entre/pelas identidades determinadas pelas faixas etárias diversas, muitas vezes, não é considerado "normal". Para a análise, seguem abaixo, três webtirinhas da Dona Anésia (Imagem 1, Imagem 2 e Imagem 3):

Imagem 1 - Dona Anésia e o neto criança - Normal
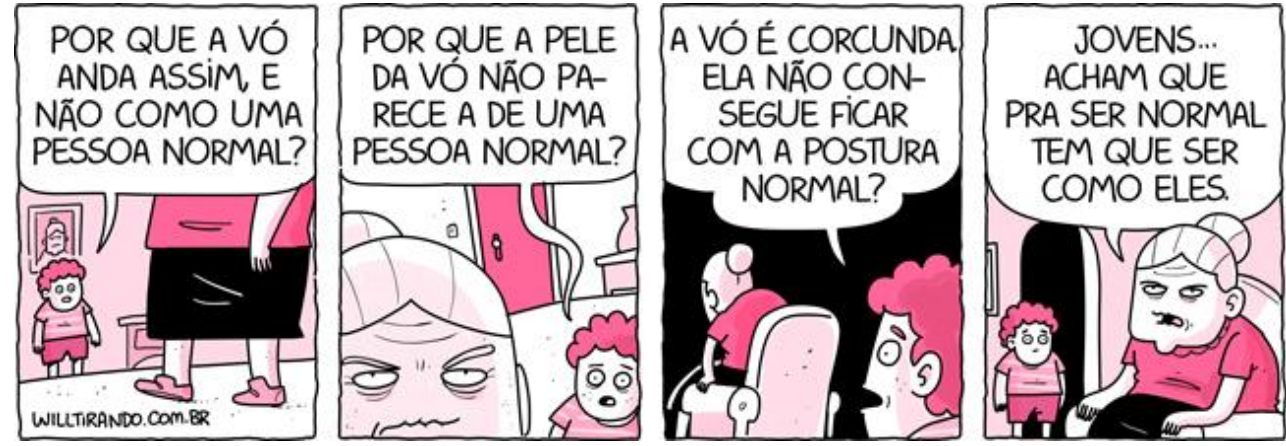

Fonte: WillTirando9.

\footnotetext{
${ }^{9}$ Disponível em: <http://www.willtirando.com.br/anesia-474/>. Acesso em: 8 ago. 2020.
} 
Conforme podemos observar, as webtirinhas da Dona Anésia, criadas em ambiente digital, possuem as mesmas características das tirinhas tradicionais, seu gênero originário: há balões para introdução das falas, enquadramentos em sequência, ambientação e cenas curtas e o padrão de cores, traços e feições das personagens se mantêm em todas as tirinhas, estabelecendo a identidade artística. No contexto desta criação, a cor predominante é vários tons de rosa, distribuídos em todas as cenas. Como arquitetônica do gênero discursivo verbovisual webtirinha, sua leitura e compreensão se dão como um todo e não atingiria seu objetivo, não promoveria o sentido, caso o verbal e o visual estivessem separados. Enquanto gênero discursivo pautado no humor, a quebra de expectativa ocorre no último quadrinho. A expressão das personagens é peça-chave para a leitura das tiras.

Nesta webtirinha, têm-se as personagens Dona Anésia e seu neto criança. A interação entre os dois se dá devido à observação do neto a respeito das características corpóreas da avó tais como a maneira como ela anda, a pele de seu rosto e sua postura que são, para ele, diferentes e estranhas. Aqui, há uma comparação entre o corpo do neto - e de outros corpos com os quais ele tem contato e, provavelmente, considera "normais" - e o corpo da avó, que difere desses corpos com os quais está acostumado. Em todos os quadros, chamamos a atenção para a palavra normal, que significa certo, correto, aceito, adequado, dentro de um padrão já estabelecido, conforme a regra etc. Nesse sentido, tudo o que está fora desse campo discursivo é, automaticamente, considerado anormal, ou seja, atípico, incomum, irregular, inusitado, inusual, raro, singular, inabitual, entre outros.

Entendemos que o discurso que emerge por meio deste enunciado verbovisual (Imagem 1) diz respeito ao que é e ao que não é considerado "normal" sobre os corpos dos jovens e os corpos dos idosos. Como consequência dessa interação entre avó e neto, constatase que a velhice está no patamar/categoria de "anormalidade", pois o andar, a pele e a postura da Dona Anésia não são como os corpos que o neto considera "normais", ou seja, determinada forma de andar é normal, outras não; determinada textura da pele do rosto é normal, outras não; determinada postura é normal, outras não.

Sendo o corpo da Dona Anésia uma ruptura de tantas "normalidades", ela é, portanto, anormal, fora do padrão jovem. Nesta webtira, podemos inferir que as identidades que se estabelecem a partir da interação dos sujeitos discursivos, avó e neto, são de que as pessoas mais velhas, os idosos, não são pessoas normais, ou, pelo menos, não são normais mais, pois deixaram de se enquadrar em determinadas características consideradas aceitas, socialmente, no que diz respeito aos corpos das pessoas. 
No final da webtira, Dona Anésia conclui que os jovens acreditam que ser diferente deles significa não ser normal. A fala no último quadrinho é uma crítica sobre o estabelecimento de padrões designados para as diferentes faixas etárias a partir de características corpóreas, sendo um deles superior aos outros, neste caso, o padrão dos corpos dos jovens. Na segunda webtirinha em análise, ocorre, novamente, o uso da palavra normal, mas, desta vez, é a Dona Anésia que se dirige ao neto adolescente e, nessa interação discursiva, quem está fora da "normalidade" é ele, como vemos a seguir:

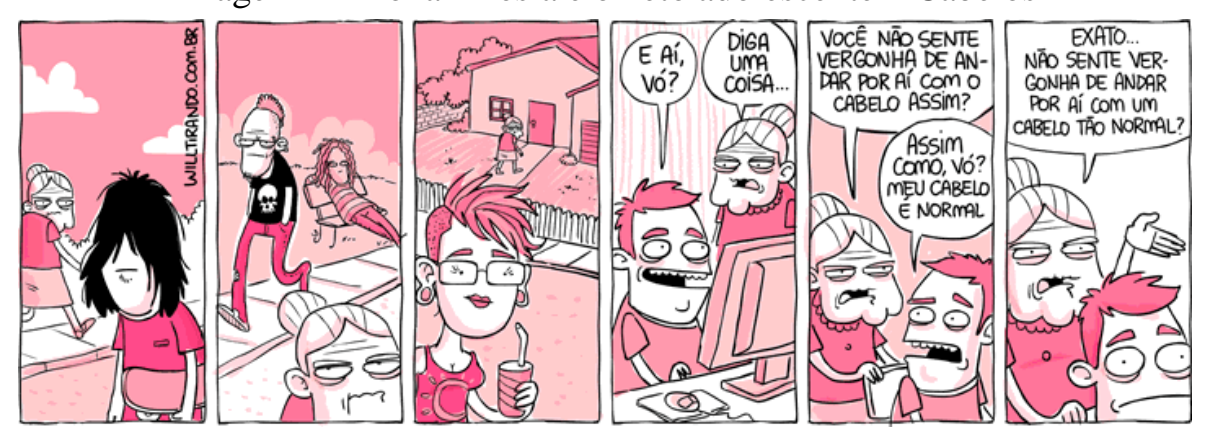

Fonte: WillTirando ${ }^{10}$.

Não há enunciado verbal nos três primeiros quadros (em um total de seis enquadramentos), porém, o visual se encarrega da comunicação que deve ser estabelecida, trazendo um dado que será criado mais a frente, na finalização da webtira. Nesses quadros iniciais, a Dona Anésia observa jovens pelas ruas mas, ao entrar em casa, se depara com seu neto adolescente que é/está diferente do que ela pôde observar: ele não se enquadra nos padrões vistos por ela, acerca dos sujeitos jovens, enquanto esteve fora.

Dona Anésia, ao perceber isso, o questiona e pergunta se ele não sente vergonha de "andar por aí com um cabelo tão normal", presumindo, assim, que as identidades que se dão a partir das características e peculiaridades preestabelecidas para esse grupo social é a de que os jovens devem ser "diferentes", "autênticos", "originais" e não "normais" como ela constata a respeito do neto adolescente. Nesse contexto, a normalidade é determinada pelo tipo de corte de cabelo, e é o que difere o neto da Dona Anésia dos outros sujeitos de seu grupo social.

Percebemos, na webtirinha, portanto, que i) a Dona Anésia acha estranho o neto adolescente não ter determinadas características semelhantes a de outros jovens; ii) que ele não faz ideia do motivo pelo qual a avó pergunta sobre seu cabelo (já que ele não teve acesso ao dado anterior que baseou a análise, pois não estavam juntos quando ela pôde observar os

${ }^{10}$ Disponível em: <http://www.willtirando.com.br/anesia-110/>. Acesso em: 8 ago. 2020. 
cabelos de outros jovens na rua); iii) e que a Dona Anésia tira conclusões a respeito do comportamento, estética corporal e estilo dos jovens. Novamente, a constatação acerca da normalidadelanormalidade se dá a partir da observação do corpo, neste caso, mais especificamente, dos diferentes estilos de cabelo.

Na webtirinha em análise, mais uma vez, as identidades são estabelecidas a partir da faixa etária e dos padrões determinados para cada um dos grupos sociais envolvidos na comunicação discursiva em questão, assim como ocorre na Imagem 1. Ao analisarmos as imagens 1 e 2, observamos que as identidades oscilam: ora a Dona Anésia é enquadrada como "anormal” pelo fato de ser idosa, ora é o neto que não responde aos quesitos básicos do que é ser jovem, sendo, também, "anormal".

Nesse contexto, entendemos, assim como Silva (2000), que "fixar uma determinada identidade como a norma é uma das formas privilegiadas de hierarquização das identidades e das diferenças" (SILVA, 2000, p. 83), ou seja, "normalizar significa atribuir a essa identidade todas as características positivas possíveis, em relação às quais as outras identidades só podem ser avaliadas de forma negativa" (SILVA, 2000, p. 83). Assim, em movimento de pêndulo, há uma tentativa de fixação das identidades, tanto para o jovem quanto para o idoso, sendo tal tentativa determinada a partir de concepções sobre os corpos e estéticas preestabelecidas para cada uma dessas categorias, via atos de criação linguística e discursos materializados em enunciados verbovisuais.

Já na terceira webtirinha (Imagem 3), a seguir, temos uma sequência de 4 quadrinhos em que Dona Anésia e Dolores fazem uma pesquisa com pessoas na rua para saberem se o fato de idosos terem interesse em fazer faculdade é algo considerado aceito e bem visto pela sociedade: 
Imagem 3 - Dona Anésia e Dolores - Trabalho faculdade
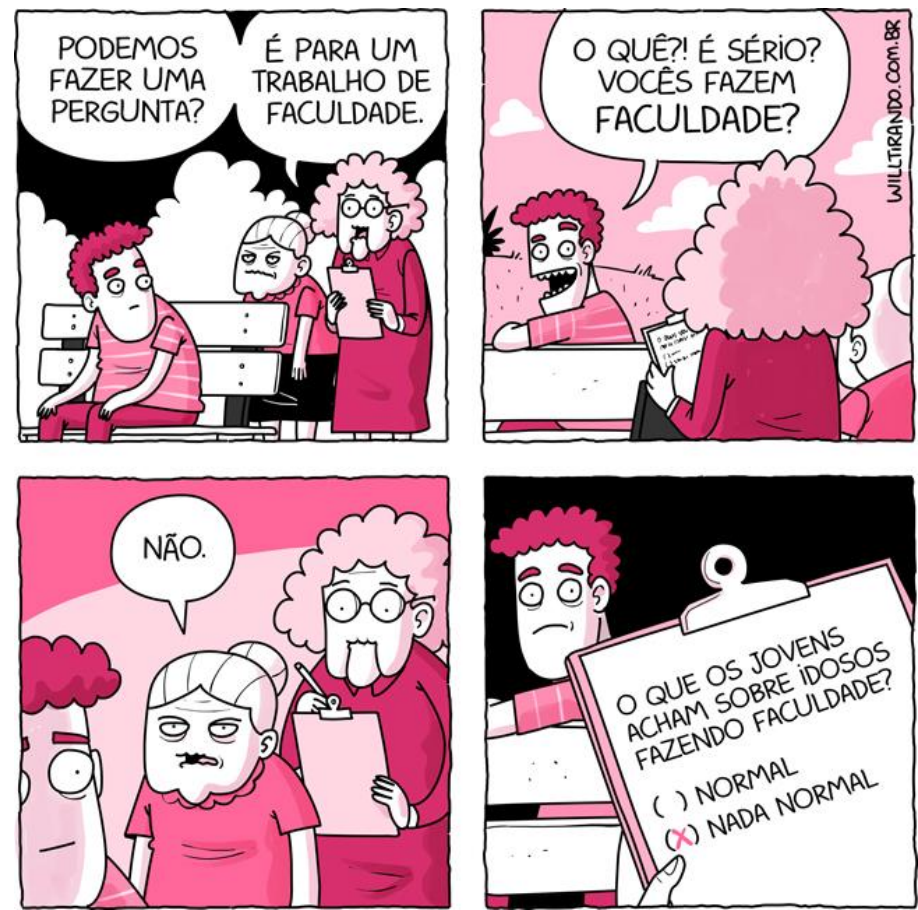

Fonte: WillTirando ${ }^{11}$.

Dona Anésia e Dolores presumem que as respostas para a pergunta $O$ que os jovens acham sobre idosos fazendo faculdade? serão dadas na relação entre "normal” e "não normal”, portanto, inserem em seu questionário apenas duas opções de resposta: ( ) normal e ( ) nada normal. O sintagma "nada", nesse enunciado, enfatiza que o interesse dos idosos em fazer faculdade pode ser considerado absurdo, fora do tempo que se espera que uma pessoa curse uma faculdade, totalmente fora da "normalidade", ou seja, nada normal. E é exatamente isso que elas constatam quando pedem permissão para fazer uma pergunta a um rapaz sentado em um banco de praça e ele se espanta quando Dolores afirma que a pesquisa é para um trabalho da faculdade.

Nesta webtirinha, ocorre a determinação/imposição/representação de comportamentos, lugares e posições que devem ou não ser ocupados por pessoas que tem mais idade. Mesmo com as mudanças de nomenclatura, dos reconhecimentos dos diversos saberes a respeito dos idosos, da quebra de paradigmas que designam tais sujeitos (de "velhice" para "terceira idade" e, em alguns casos, até mesmo, "melhor idade), ainda há uma concepção arraigada na sociedade de que o idoso não é capaz, de que o tempo dele já passou, de que não há finalidade em estudar uma vez que ele (idoso) não terá tempo de vida para usufruir daquilo que o estudo

\footnotetext{
${ }^{11}$ Disponível em: <http://www.willtirando.com.br/anesia-449/>. Acesso em: 8 ago. 2020.
} 
lhe proporciona, ou seja, que as pessoas mais velhas devem fazer outras coisas, que seus espaços são outros, não a universidade, por exemplo.

No entanto, o desejo de Dona Anésia e Dolores de realizarem atividades que não são consideradas "normais" para os mais velhos - especialmente para as mulheres idosas, culturalmente fadadas a cuidarem dos afazeres domésticos e da família - mostra que:

Ao observar as manifestações culturais daqueles que envelhecem na contemporaneidade, identificamos mudanças significativas de hábitos, imagens, crenças e termos utilizados para caracterizar esse período da vida. Além das tradicionais representações que atrelam os momentos mais tardios da vida ao descanso, à quietude e à inatividade, surgem hábitos, imagens e práticas que associam o processo de envelhecimento a atividade, aprendizagem, flexibilidade, satisfação pessoal e vínculos amorosos e afetivos inéditos. $O$ espectro de descrições possíveis para o envelhecimento ampliou-se tanto que à 'velhice', tal como a conhecemos, se somou a 'terceira idade' e uma série de características inéditas que a acompanham (SILVA, 2008, p. 156).

Em consonância com as peculiaridades que surgem devido à mudança de comportamento das pessoas com mais idade, em processo de imbricamento entre velhice e terceira idade, surgem, também, novas identidades, que oscilam ora para o que possa ser remetido à quietude da velhice, ora ao protagonismo vislumbrado na terceira idade e suas possibilidades. No entanto, ao hierarquizar determinadas identidades, outras são apagadas, pois as identidades nunca são naturais e, sim, estabelecidas em relações de poder. O escape a essas imposições são formas de tais sujeitos resistirem às imposições, nas análises em questão, relacionadas ao corpo e aos espaços que esses corpos podem ou devem ocupar.

Dessa maneira, a fixação de identidade(s) é um processo de esforço sem fïm. Mesmo que haja, o tempo todo, tentativas e tendências para a fixação, por serem atos de criação linguística, elas se tornam impossíveis, pois a língua e a linguagem não são estanques e a comunicação discursiva são movimentos dialógicos incessantes e não produtos. Nesse contexto de interação entre os sujeitos do discurso, Bakhtin afirma que:

O mundo, em seu dado, não adquire um significado positivo para mim senão enquanto ambiente do outro. Todas as determinações e as caracterizações do mundo que lhe asseguram o acabamento, [...] são feitas através dos valores do outro - do outro que é seu herói. Esse mundo, essa natureza, essa história, essa cultura, essa visão do mundo decorrente daí, tudo isso, enquanto validado, sem levar em conta o sentido, enquanto reunido e acabado pela memória eterna, é apenas mundo, natureza, cultura do homem-outro. Tudo o que determina e caracteriza a existência em sua atualidade que lhe insufla sua dinâmica dramática [...] arde com o fogo emprestado da alteridade (BAKHTIN, 2011, p. 148, grifos do autor). 
Entendemos, portanto, assim como Bakhtin, que o pilar para a constituição do sujeito e suas possíveis e pendulares identidades, é a alteridade, ou seja, a constituição do sujeito se dá a partir das relações que se estabelecem entre o eu e o outro, em situações comunicativas suportadas e possíveis de se realizarem via gêneros discursivos de materialidades diversas, possibilitados por meio de esferas de atividade humana plurais, pois "o discurso sempre está fundido em forma de enunciado pertencente a um determinado sujeito do discurso, e fora dessa forma não pode existir" (BAKHTIN, 2011, p. 274).

\section{Considerações finais}

Em nosso estudo, as webtirinhas são um gênero discursivo verbovisual, uma vez que aliam o verbal e o visual fazendo emergir sentidos em sua arquitetônica. Assim como as tiras impressas, são curtas, discorrem sobre temas corriqueiros e têm personagens fixas em histórias que se desenrolam no dia a dia. Além disso, promovem quebra de expectativa via sátiras e ironias com humor, no entanto, sua produção, suporte e acesso mudam por serem digital. Mesmo em situações inicialmente consideradas simples e sem importância, tanto as tiras como as webtiras trazem à tona reflexões, críticas e posicionamentos.

O surgimento deste gênero discursivo verbovisual se dá devido ao imbricamento de esferas de atividade humanas midiáticas possibilitadas pela convergência cultural debatida em Jenkins (2008). No caso em questão, tal fenômeno ocorre, especialmente, pela coalisão de mídias impressas e digitais, pela cultura participativa e pela economia afetiva. A convergência cultural abre espaço para que os sujeitos tenham acesso a diversos conteúdos de maneira mais dialógica, com liberdade de escolhas que vão além do que o cooperativismo midiático quer nos transmitir em suas mídias tradicionais, como tem sido desde a invenção da imprensa.

Por ser um gênero ágil e pautado no humor, a relevância das tirinhas e webtirinhas para a questão das identidades, a princípio, pode passar despercebida, pois o gênero é visto para ser "consumido" rapidamente, promovendo o entretenimento imediato. No entanto, uma das peculiaridades do humor é trazer, de maneira velada (ou não), sarcástica e irônica, críticas, reflexões e deslocamentos. Nesse sentido, em nossas análises, podemos perceber que as identidades se dão a partir das relações intersubjetivas estabelecidas nos embates ideológicos constantes entre identidade(s) e diferença(s), sempre na alternância dos sujeitos discursivos via alteridade, pois é por meio dessas relações que os sujeitos se constituem. 
A esse respeito, entendemos que a constituição do sujeito idoso se dá nas diversas situações e interações discursivas, na relação de si mesmo e com o outro, via discursos que emergem em enunciados de semioses variadas. O corpus deste trabalho nos permite perceber que, apesar das gradativas mudanças de paradigmas a respeito do sujeito idoso e de seu papel na sociedade, ainda há muita dificuldade e, até mesmo, certa resistência em entender que outros espaços podem e devem ser ocupados por esse grupo social. Tal dificuldade se intensifica quando nos referimos às mulheres, pois sempre lhes foi imposto o papel de cuidadoras do lar e de sujeitos sem voz na história do mundo. No entanto, há a possibilidade, na contemporaneidade - mesmo que ainda não ideal -, de que as mulheres idosas possam protagonizar a sua própria história, pois a velhice/terceira idade é predominantemente feminina.

A busca deste protagonismo emerge nas webtirinhas da Dona Anésia, que, além das situações cotidianas as quais a protagonista encena, o uso do pronome de tratamento "Dona" (que constitui a denominação da personagem juntamente com o seu nome próprio) vai além de sua recorrência habitual que diz respeito à abordagem respeitosa dada às mulheres casadas e/ou idosas. Tal pronome promove a ruptura da identidade do sujeito mulher idosa, nos levando a crer que além de idosa, a Dona Anésia é "dona de si”, independente, rompendo estereótipos de dependência dos mais velhos em relação aos jovens e do papel da mulher enquanto coadjuvante e sujeitada aos desígnios do matrimônio e da maternidade. Retomando a frase no início deste trabalho, é preciso lembrar que, ao cuidar dos idosos e permitir/promover que eles sejam sujeitos autônomos e respaldados pelos cuidados que lhes são direitos, é poder vislumbrar o futuro, e perceber qual velhice/terceira idade/melhor idade haverá para os jovens atuais, uma vez que "nada deveria ser mais esperado e, no entanto, nada é mais imprevisto que a velhice" (BEAUVOIR, 1970, p. 11).

As análises realizadas neste estudo, mesmo que breves - pois inúmeros olhares podem ser dados a um mesmo objeto, sendo impossível esgotá-lo - demonstram a relevância do tema para os estudos do discurso, no que diz respeito às diversas materialidades que vão além do verbal, emergindo/transformando/ampliando gêneros discursivos infinitos, possibilitando embates ideológicos via enunciados e discursos. Devido à constituição do sujeito que por meio dessas materialidades se constitui continuamente, o estudo do tema do sujeito idoso não se encerra aqui, promovendo potencial debate no que se refere à questão da identidade, pois, segundo Silva (2000), as identidades são construídas na relação e nos enfrentamentos com as diferenças em atos de criação linguística, em nosso trabalho, podendo ser analisadas, também, em esferas discursivas e dialógicas. 


\section{Referências}

BAKHTIN, Mikhail. Os gêneros do discurso. Tradução Paulo Bezerra. São Paulo: Editora 34, 2019.

BAKHTIN, M. M. Estética da criação verbal. Tradução Paulo Bezerra. São Paulo: Martins Fontes, 2017.

BAKHTIN, Mikhail. Problemas da Poética de Dostoievski. 5. ed. Tradução direta do russo, notas e prefácio Paulo Bezerra. Rio de Janeiro: Forense Universitária, 2010.

BEAUVOIR, Simone. A velhice. Rio de janeiro: Nova Fronteira, 1970.

JENKINS, Henry. Cultura da Convergência. Tradução Susana Alexandria. São Paulo: Aleph, 2008.

LISBOA, Loraine Vidigal. Memes jurisprudenciais no facebook do STJ: a constituição dialógica de um gênero verbo-visual. 2015. 107 f. Dissertação (Mestrado em Estudos da Linguagem) - Universidade Federal de Goiás - Regional Catalão, Catalão, 2015.

NAVARRO, Pedro. Enunciado, subjetivação e "melhor idade". Estudos Linguísticos (São Paulo. 1978), v. 40, p. 1551-1561, 2011. Disponível em: <https://revistas.gel.org.br/estudoslinguisticos/article/view/1277>. Acesso em: 20 jul. 2020.

NICOLAU, Vitor. Tirinhas \& mídias digitais: a transformação deste gênero pelos blogs [recurso eletrônico]. João Pessoa: Marca de fantasia, 2013.

SILVA, Luna Rodrigues Freitas. Da velhice à terceira idade: o percurso histórico das identidades atreladas ao processo de envelhecimento. História, Ciências, Saúde Manguinhos, Rio de Janeiro, v. 15, n. 1, p. 155-168, jan.-mar. 2008. Disponível em: $<$ http://www.scielo.br/scielo.php?script=sci_arttext\&pid=S0104-

59702008000100009\&lng=en\&nrm=iso>. Acesso em: 20 jul. 2020. DOI: https://doi.org/10.1590/S0104-59702008000100009

SILVA, Tomaz Tadeu. A produção social da identidade e da diferença. In: SILVA, T. T. (org.). Identidade e diferença. A perspectiva dos Estudos Culturais. Petrópolis: Vozes, 2000, p. 73-102.

STAFUZZA, Grenissa Bonvino. O Círculo de Bakhtin (Volóchinov e Medviédev) no Brasil: episteme, autoria e tradução em perspectiva dialógica. Revista Heterotópica, v. 1, n. 1, p. 6682, 26 jun. 2019. Disponível em: <http://www.seer.ufu.br/index.php/RevistaHeterotopica/article/view/48519>. Acesso em: 20 jul. 2020. DOI: https://doi.org/10.14393/HTP-v1n1-2019-48519

STAFUZZA, Grenissa Bonvino. Sentidos do enunciado verbovisual em pôsteres publicitários de Bastardos inglórios. Scripta - Revista do Programa de Pós-graduação em Letras e do Centro de Estudos Luso-afro-brasileiros da PUC Minas, v. 22, n. 45, p.137-150, 2018. Disponível em: <http://periodicos.pucminas.br/index.php/scripta/article/view/17133/13828>. Acesso em: 20 jul. 2020. DOI: https://doi.org/10.5752/P.2358-3428.2018v22n45p137-150 
VOLOSHINOV, Valentín Nikoláievitch. Estrutura do Enunciado. Tradução Ana Vaz para fins acadêmicos, s/d, mimeo.

\section{Referências Eletrônicas}

Chá com Anésia \#1 - Entrevista com Will Leite. Disponível em: <https://www.youtube.com/watch?v=znRxSwwsv3M>. Acesso em: 24 fev. 2020.

Como é feito o WillTirando. Disponível em: <https://www.youtube.com/watch?v=jpS4PfBr1p8>. Acesso em: 24 fev. 2020.

Desenhando a Dona Anésia - Will Leite. Disponível em: <https://www.youtube.com/watch?v=yVMjd0yQMhM>. Acesso em: 24 fev. 2020

Dona Anésia - WillTirando. Disponível em:

<http://www.willtirando.com.br/category/anesia/>. Acesso em: 24 fev. 2020.

Recebido em: 9 de setembro de 2020

Aceito em: 13 de novembro de 2020 